\title{
Análisis fenomenológico de la imaginería sensorial en las experiencias hipnagógica e hipnopómpica*
}

\author{
Alejandro Parra \\ Facultad de Psicología \\ Universidad Abierta Interamericana
}

Recibido: 3 de octubre del 2012 / Aprobado: 27 de junio del 2013

Se estudiaron las experiencias anómalas del momento en que las personas se están quedando dormidas, como el estado hipnagógico (HG) o de cuando se despiertan del sueño, como el estado hipnopómpico (HP). Se aplicó una encuesta a 436 participantes de ambos sexos, $51 \%$ mujeres y $49 \%$ varones, de edades entre 17 y 80 años $(M=33,53)$. Se analizó la frecuencia relativa de las modalidades sensoriales de imaginería HG y HP, contenido e interpretación. Los resultados indicaron mayor proporción de respuestas HG que HP. Las experiencias más frecuentes fueron la sensación de caida, la imaginería visual, auditiva, táctil, y la sensación de presencia, seguida por sensaciones corporales y movimientos. Se presentaron pocas respuestas de imaginería olfativa y gustativa. Adicionalmente, se realizó un análisis cualitativo de ambos tipos de experiencias.

\section{hipnagógica / hipnopómpico / imaginería / alucinación / sueño}

Phenomenological analysis of sensory imagery on hypnagogic and hypnopompic experiences

This study explores anomalous experiences reported by people whence falling asleep as hypnagogic state (HG) or awakening from sleep as hypnopompic state (HP). 436 participants, 51\% female, 49\% male, ages between 17-80 years old $(M=33,53)$, responded to a survey that investigates relative frequency of sensory modalities for HG and HP imaginary, content and interpretation. Results indicate that HG responses were more common that HP. The most frequent experiences were falling sensations, visual, auditory and tactile imagery, and sensing a "presence». These were followed by bodily and movement sensations. Olfactory and taste imagery were rare. This study in complemented with a qualitative analysis of both type of experiences.

\section{hypnagogic / hypnopompic / imagery / hallucination / sleep}

1 Este estudio ha sido posible gracias a un subsidio otorgado por el Vicerrectorado de Investigación y Desarrollo de la Universidad Abierta Interamericana.

Correo electrónico: rapp@fiertel.com.ar 


\section{INTRODUCCIÓN}

Los términos «imaginería hipnagógica» e «hipnopómpica» fueron acuñados por Maury (1848) y Myers (1903), respectivamente, y se refieren a representaciones mentales de diferentes modalidades sensoriales que se experimentan en los estados fronterizos: cuando se está quedando dormido o al despertar después de dormir. A estas sensaciones y experiencias temporarias se las conoce como imaginería hipnagógico/hipnopómpica (HG/HP), es decir, la imposibilidad de moverse o de hablar (American Sleep Disorders Association, 1990). Conviene decir que ambas experiencias son similares, y por ello se pueden aplicar estas características a ambos periodos. Sin embargo, ciertas características o experiencias parecen ser más comunes en el estado hipnagógico que en el hipnopómpico (Sherwood, 2012). Las imágenes son de duración breve (Nielsen, 1992), pero pueden ser muy vívidas y realistas. Algunos autores distinguen entre imaginería que se produce en los estados hipnagógicos (Glicksohn, 1989; McKellar, 1989), pero no en los hipnopómpicos (Mavromatis, 1987).

En consecuencia, la mayoría de los estudios ha focalizado más el estado hipnagógico (el periodo entre la vigilia y el sueño; por ejemplo, el momento en que una persona se está quedando dormida) que el estado hipnopómpico (el periodo entre el sueño y la vigilia en el momento en que la persona está despertando del sueño). El estado hipnagógico es bastante complejo y está compuesto por varias etapas (Mavromatis, 1987). El periodo de «conciliar el sueño» y el «periodo del despertar» son estados únicos que no pueden ser considerados como vigilia o sueño (Hori, Hayashi \& Morikawa, 1994). Es muy difícil determinar el momento exacto en que una persona se duerme, a menos que se utilice un criterio arbitrario, debido a que la transición es gradual y porque existen grandes diferencias individuales (Lavie, 1996; Rechtschaffen, 1994).

Algunos estudios han demostrado que como se experimentan cambios a lo largo del sueño, la cantidad de imaginería hipnagógica visual por ende tiende a aumentar (Hori et al., 1994), se torna más confusa (Foulkes \& Vogel, 1965) y la calidad de la imagen, vivacidad, luminosidad e intensidad del color también aumentan (Mavromatis, 1987; Nielsen, 1992). McKellar (1989) sugirió que la forma de imaginería hipnagógica también cambia desde la secuencia de objetos, rostros, o paisajes a episodios más complejos. Aunque el estado hipnagógico (y probablemente también el hipnopómpico) tiene una única característica electrofisiológica y comportamental (Hori, Hayashi \& Morirawa, 1994), es sumamente variable y existen grandes diferencias individuales (Rechtschaffen, 1994; Tart, 1969, p. 73).

Al parecer los episodios de imaginería HG/HP a veces ocurren de manera esporádica aunque también pueden ocurrir bajo la forma de series concen- 
tradas de episodios, las imágenes son muy breves y dinámicas, pueden durar no más de un segundo o dos (Nielsen, 1992), y la imaginería hipnagógica parece ser más común que la hipnopómpica. Las primeras investigaciones estimaban que cerca del $2 \%$ de los adultos han experimentado alguna forma de imaginería hipnagógica. Investigaciones más recientes estiman que cerca del $33 \%$ (Leaning, 1925), 61-63 \% (McKe1lar, 1957; McKellar \& Simpson, 1954), o hasta el 75 \% (Glickson, 1989; Richardson, Mavromatis, Mindel, Owens, 1981; Sherwood, 2012) las han experimentado al menos en una ocasión, comparado con el 21,4 \% (McKellar, 1957) al $67,6 \%$ de la imaginería hipnopómpica (Richardson, Mavromatis, Mindel \& Owens, 1981). Otra investigación estimó que un $12,5 \%$ de la población del Reino Unido ha tenido alguna forma de imaginería hipnagógica (e hipnopómpica) al menos dos veces a la semana (Ohayon, Priest, Caulet \& Guilleminault, 1996).

Aunque las modalidades visuales y auditivas son dos de las formas más comunes de imaginería HG/HP (Foulkes \& Vogel, 1965; Hori, Hayashi \& Morirawa, 1994; McKellar \& Simpson, 1954), también pueden ocurrir la olfativa (olores), gustativa (sensaciones agradables o desagradables en la boca), táctil (sensación de contacto), térmica (frío o calor intensos que se experimentan como provenientes del exterior), y cenestésica (sensación de movimiento) (Leaning,
1925; Mavromatis, 1987; Schacter, 1976). Una sensación de presencia es también una modalidad HG/HP bastante común, normalmente ocurre con los ojos cerrados, aunque también puede ocurrir con los ojos abiertos (Gurney, Myers \& Podmore, 1886; Leaning, 1925; McKellar, 1989; McKellar \& Simpson, 1954). Ocasionalmente, las imágenes pueden ser más en blanco y negro que en color (McKellar, 1984; McKellar \& Simpson, 1954; Sherwood, 2001), pueden ser pequeñas (micropsias) o gigantescas (megalopsias), aunque también bajo diferentes tamaños y formas (Leaning, 1925; Mavromatis, 1987; McKellar, 1957; McKellar \& Simpson, 1954). Otras veces las imágenes aparecen curiosamente iluminadas o se las puede ver como desde un ángulo en particular (Leaning, 1925; Mavromatis, 1987; McKellar, 1957).

Estos estados también pueden ser propicios para la ocurrencia de experiencias paranormales, pero también podría facilitar la interpretación errónea de experiencias «normales» (Sherwood, 2000, 2002). Se ha encontrado que las personas que tienen más experiencias $\mathrm{HG} / \mathrm{HG}$ o parálisis del sueño en la infancia también tienen más experiencias anómalas en la edad adulta (Sherwood, 2000). Más concretamente, la imaginería $\mathrm{HG} / \mathrm{HP}$ está asociada a experiencias de percepción extrasensorial, apariciones y comunicación con los muertos, experiencias fuera del cuerpo, recuerdos de vidas pasadas y experiencias relacionadas con abducciones ex- 
traterrestres (por ejemplo, Glicksohn, 1989; Gurney, Myers \& Podmore, 1886; Leaning, 1925; McCreery, 1993; McKe1lar, 1957; Mavromatis, 1987; Spanos, Cross, Dickson \& Dubreuil, 1993). Por lo tanto, es importante investigar el tipo de imágenes y experiencias que ocurren en estos estados y la forma en que estas se interpretan.

Estudios experimentales previos y encuestas se han centrado más en la imaginería hipnagógica (HG) (Mavromatis, 1987; Schacter, 1976), y algunos artículos más sobre la hipnopómpica (HP) (Gillespie, 1997). Este sesgo parece comprensible, en cierta medida, teniendo en cuenta que la HG parece ser más común que la HP. Las encuestas estiman que alrededor del 33,75\% (Glicksohn, 1989; Leaning, 1925; McKellar, 1957; McKellar \& Simpson, 1954; Richardson, Mavromatis, Mindel \& Owens, 1981), de las personas han experimentado imaginería $\mathrm{HG}$ en al menos una ocasión, en comparación con el 1,4\% (McKellar, 1957) a 67,6\% de imaginería HP (Richardson et al., 1981). Un estudio a gran escala estimó que el $37 \%(12,5 \%)$ de la población ha experimentado alguna forma de imaginería HG (o HP) por lo menos dos veces a la semana durante el año (Ollayon, Priest, Caulet \& Guillerninault, 1996). Estas estimaciones diferentes pueden ser el producto de las técnicas de estudio y terminologías diferentes utilizadas en estas investigaciones y el hecho de que no todo el mundo puede recordar sus experiencias $\mathrm{HG} / \mathrm{HP}$.

Aparte de focalizarse en la imaginería $\mathrm{HG}$, los investigadores se han centrado también en las modalidades visuales y auditivas que parecen ser la forma más común de imaginería $\mathrm{HG}$ (Foulkes \& Vogel, 1965; Hori, Flayashi \& Morikawa, 1994; McKellar \& Simpson, 1954; Mavromatis, 1987; Schacter, 1976). Sin embargo, se sabe relativamente poco acerca de las imágenes que se producen en otras modalidades sensoriales, como olfativa, gustativa (sabores), táctil, térmica, cinética, corporal y sensaciones sinestésicas, además de la sensación de presencia (Leaning, 1925; Mavromatis, 1987; Schacter, 1976). También se sabe que pueden ocurrir en más de una modalidad sensorial simultáneamente (por ejemplo, McKe1lar, 1957; McKellar \& Simpson, 1954; Mavromatis, 1987; Oswald, 1962). Estas combinaciones de imágenes pueden mejorar el grado de realismo de la experiencia; es decir, cuanto mayor sea el número de diferentes atributos, más alucinatoria será la experiencia (Nielsen, 1992).

Los intentos de clasificar el contenido de las imágenes también se han centrado en la imaginería HG, en particular las imágenes visuales (Leaning, 1925; Mavromatis, 1987). Leaning (1925) identificó cinco categorías de imaginería visual HG: a) amorfas (por ejemplo, manchas o nubes de luz), b) rostros, c) 
diseños y objetos, d) paisajes, y e) escenas. Mavromatis (1987) clasificó seis: a) amorfas; b) con diseño; c) rostros, figuras, animales y objetos; d) escenas de la naturaleza; e) escenas con personas; y f) escritos. A continuación, transcribiré cinco experiencias $\mathrm{HG} / \mathrm{HP}$ que ilustran algunas características anómalas (Parra, 2009). Martín, de 30 años, relata la siguiente experiencia:

Cierta noche, cuando estaba por dormir $[\mathrm{HG}]$, desperté con un fuerte ruido y veo que la puerta se abre. Vi la sombra de un hombre grande y alto que ingresaba a la habitación y me tomaba de las piernas por los tobillos y me quería llevar con él. Me jaló de los pies. Grité muy fuerte. Mi tío entró a la habitación y no había más que mis dos primos que escucharon todo, pero no vieron nada porque estaba a oscuras; mis primos estaban atemorizados a causa de mis gritos. Mi tío vio mis tobillos golpeados. Para mí todo esto fue tan real, pero no sé qué fue lo que vi ni lo que me agarró.

Otras veces puede anunciar un evento importante o ser solo un presentimiento. El siguiente es un relato de Roxana, de 31 años:

Me eché en el sofá para dormir la siesta. Me costaba dormir, pero aún y todo conseguí conciliar un sueño profundo. De repente, en el entresueño [HG], vi a mi padre en el sofá y su brazo tenía una mancha roja. Me desperté sobresaltada con una sensación de angustia; de que algo malo iba a pasar sin que nada pudiera quitarme aquella sensación. Al final del día me obligué a olvidar aquella sensación. Diez días después me llamó mi madre diciendo que mi padre estaba en el hospital porque se dio un golpe con una puerta en el cuello mientras estaba trabajando y que se le hinchó el brazo por la hemorragia interna provocada por el golpe.

Kristina, de 50 años, relata otra experiencia premonitoria durante el estado hipnagógico, que involucra un anuncio espiritual:

Mientras me estaba durmiendo [HG] tuve la visión de dos ángeles que se estaban llevando a otra persona. La imagen de esa persona estaba rodeada de una nebulosa blanca a mi alrededor. Me vino la idea de muerte y pensé que se trataba de mi hija, porque en ese momento estaba hospitalizada. Era como un presentimiento de que algo malo iba a pasar pero no sabía qué. Llamé al hospital y mi hija estaba bien. Entonces, no me preocupé. Tres días después, mi hermana me dijo que mi sobrino Ariel -de 24 años- había tenido un accidente con la moto aquella madrugada, justo cuando me estaba quedando dormida.

McKellar (1957, p. 35) señala que las experiencias HG/HP pueden signifi- 
car cosas muy distintas para diferentes personas. Sin embargo, no parece haber habido mucha investigación sobre el tipo de interpretaciones que las personas dan a estas experiencias. Algunos hasta pueden incluso estar preocupados de si estas experiencias son patología física o mental (McKellar, 1957; Rose \& Blackmore, 1996). Otras personas pueden no estar muy preocupadas por sus experiencias, pero otros pueden encontrarlas desconcertantes o mostrar el deseo de explicarlas, como la de Joaquín T., de 43 años:

En el momento que me estaba despertando [HP], siento que alguien se sube a mi cama se acuesta sobre mí y no me deja mover ni un dedo, ni respirar. Me da pánico y me despierto aun sin poder moverme en ese momento.

O el caso Maritha C., de 20 años, quien describe su experiencia:

[...] me ha ocurrido que cuando me estaba por despertar [HP], siento que alguien pasa... me da pánico, se me sube a mi cama, se acuesta sobre mí y no me deja despertar. Aun sin poder moverme en ese momento me da pánico, me cuesta trabajo salir de ese trance.

Algunas personas pueden suscribir a una interpretación paranormal o sobrenatural de sus experiencias HG/HP (por ejemplo, Hufford, 1982; Leaning, 1925; Liddon, 1967; McKellar, 1957, 1989).

\section{Objetivos}

Se sabe poco en general acerca de estas experiencias durante el periodo hipnopómpico (HP), en comparación con el HG. No existen estudios sobre estas experiencias en muestras latinoamericanas, excepto algunos estudios en Argentina (Parra, 2009; Parra \& Villanueva, 2010). En consecuencia, los objetivos de este estudio son investigar:

1. El tipo de sensaciones y sentimientos que se experimentan durante los periodos HG y HP, y las características que comparten.

2. La frecuencia relativa de las diferentes modalidades sensoriales de experiencias $\mathrm{HG} / \mathrm{HP}$.

3. El contenido de cada tipo de imágenes.

4. Similitudes/diferencias de estas sensaciones con los sueños.

5. Posibles interpretaciones para estas sensaciones.

MÉTOdo

\section{Participantes}

Los participantes fueron 436 adultos de ambos sexos, 222 (51 \%) mujeres y 214 (49\%) varones, de edades comprendidas entre los 17 y 80 años (me$\mathrm{dia}=33,53$, DT $=13,67$ ), en su mayoría estudiantes del campus sur de la Universidad Abierta Interamericana de Buenos Aires. Ya que estaba interesado en la obtención de tantos casos como 
sea posible, se incluyeron también personas que no eran estudiantes (cinco por cada estudiante), entre familiares y amigos.

\section{Instrumentos}

\section{Encuesta de Experiencias Relacio-} nadas con el Sueño (EERS; Sherwood, 2012). Es una encuesta autoadministrable de catorce ítems. Cada ítem se refiere a dos periodos diferentes: cuando está durmiendo (estado hipnagógico o HG) y cuando está despertando (estado hipnopómpico o HP) que se responde Sí/No. Además, cada ítem contiene un espacio corto para responder libremente qué tipo de sensación acompañó cada cualidad sensorial de la experiencia HG/ HP durante el último mes, tales como imaginería visual, auditiva, olores, sabores, sensación de tocar o ser tocado por alguien o por algo, sensación inusual relacionada con el cuerpo, sensación de caída, movimiento, sonidos reales, incapacidad para moverse o hablar, sensación de presencia, semejanza-diferencia con los sueños, e interpretación de las experiencias HG/HP. Se adicionó una pregunta sobre Espiritualidad («No soy espiritual» a «Soy muy espiritual»), frecuencia de recuerdo de sueños ( «Casi todas las mañanas» a «Casi nunca») y nitidez de las imágenes de los sueños («Perfectamente clara e intensa» a «Tan vaga y difusa que resulta imposible discernir»). A menos que se indique lo contrario, todas las preguntas refieren a sensaciones o sentimientos que son esencialmente «imaginarios», es decir, que no parecen ser resultado de estimulación externa, aunque con frecuencia pueden ser muy vívidas y realistas. La EERS es esencialmente una encuesta exploratoria y cualitativa, que apunta a identificar y describir temas relacionados con el contenido y la interpretación de las experiencias $\mathrm{HG} / \mathrm{HP}$.

\section{Procedimiento y análisis}

La escala contiene instrucciones antes de responder, con el siguiente texto:

Si nunca ha experimentado una sensación o sentimiento especial, quedándose dormido o despertando del sueño, las preguntas que siguen sobre estas experiencias no se aplican a usted. Si este es el caso, es decir, si usted contestó NO, por favor, pasar a la siguiente pregunta. Algunas experiencias son relativamente más comunes que otras y por lo tanto no todo el mundo las ha tenido. Si no está seguro de que ha tenido una de estas experiencias en particular, por favor, responda NO.

Aplicamos una técnica de muestreo no-probabilística para obtener el mayor número de casos para analizar. Seis encuestas fueron entregadas a cada estudiante para sus familiares, amigos y para sí mismo/a. El tiempo promedio para completarla totalmente fue de aproximadamente 15 minutos. Todos 
los participantes recibieron una vaga información del objeto de estudio, y se les invitó a participar voluntaria y anónimamente. Los análisis fueron procesados mediante el programa estadístico SPSS 19 (en español), el nivel de $p$ fue ajustado a 0.05 , y fueron evaluados a dos colas.

\section{RESULTADOS}

Análisis descriptivo

La tabla 1 también muestra que al menos la tercera parte de los participantes han experimentado al menos una experiencia HG, tales como sensación de caí- da, seguida de visiones (principalmente a ojos cerrados e imágenes en colores), sensación de presencia, percepciones reales de movimientos y sonidos, audiciones, sensación de contacto, de incapacidad para hablar, movimientos $\mathrm{u}$ otras sensaciones. Son relativamente pocos los participantes que experimentaron olores o sabores. La sensación de caída, imaginería visual, sensación de presencia e imaginería auditiva y corporal tienden a ser mucho más comunes durante el periodo HG que en el HP. Aunque sensaciones de olores y sabores tienden a ser tan comunes durante el HG como en el HP.

Tabla 1

Datos descriptivos de experiencias relacionadas con el sueño

\begin{tabular}{lcc}
\hline Experiencias relacionadas con el sueño & HG (\%) & HP (\%) \\
\hline 1. Sensación de caída & $133(30,5)$ & $48(11,0)$ \\
2. Visiones & $120(27,5)$ & $66(15,1)$ \\
a)A ojos abiertos & $40(9,2)$ & $31(7,1)$ \\
b) A ojos cerrados & $80(18,3)$ & $35(8,0)$ \\
d) Imágenes a colores & $78(17,9)$ & $37(8,5)$ \\
3. Sensenes en blanco y negro o grises & $34(7,8)$ & $35(8,0)$ \\
4. Movimiento o sonidos reales & $87(20,0)$ & $60(13,8)$ \\
5. Audiciones & $82(18,8)$ & $42(9,6)$ \\
6. Sensación de tocar o ser tocado por alguien o algo & $69(15,8)$ & $52(11,9)$ \\
7. Incapacidad para moverse o hablar & $64(14,7)$ & $43(10)$ \\
8. Movimientos & $61(14,0)$ & $50(11,5)$ \\
9. Sensación inusual relacionada con su cuerpo & $49(11,2)$ & $33(7,6)$ \\
10. Sensación no mencionada en preguntas anteriores & $38(8,7)$ & $27(6,2)$ \\
11. Olores & $24(5,5)$ & $11(2,5)$ \\
12. Sabores & $22(5,0)$ & $26(6,0)$ \\
\hline
\end{tabular}




\section{Análisis cualitativo}

Se llevó a cabo un análisis cualitativo temático (Flick, 1998, pp. 192-198) de las respuestas textuales de la encuesta de experiencias relacionadas al sueño. Este tipo de análisis es útil cuando las experiencias $\mathrm{HG} / \mathrm{HP}$ se describen con mucho texto y se está tratando de identificar la estructura de los datos usando un método apropiado para procesar la información. Este análisis es un proceso iterativo que involucra repetidos exámenes de datos y reajustes a determinados temas.

En un principio, el autor leyó todos los datos en bruto de experiencias HG/ HP para cada pregunta con el fin de familiarizarse con estas. Luego releyó las respuestas HG (por ejemplo, en relación con imaginería visual) buscando expresiones comunes. Hay que tener en cuenta que debido a la naturaleza cualitativa del análisis, no está disponible el dato cuantitativo relacionado con la frecuencia relativa de cada tema; sin embargo, las tres primeras experiencias (o la primera o segunda) listadas en cada periodo presentan la mayor frecuencia en la descripción libre para cada participante. Cada respuesta de la encuesta se distribuye en dos columnas.

La sensación de caída es la experiencia más común y ocurrió en un $30 \%$ para el periodo HG y $11 \%$ para el periodo HP. La mayoría de estas experiencias están relacionadas con caídas desde sitios altos, sensación de inestabilidad y tienden a ser más negativas que positivas. Durante el periodo HP las sensaciones son más somáticas que mentales, tales como agitación y taquicardia.

\section{Sensación de caída}

\section{HG}

Al abismo, desde un sitio muy alto, despertar brusco, caída desesperante, no llegar nunca al suelo, sensación de inestabilidad, caer a un pozo, sensación de vértigo, sensación de moverse la cama, inseguridad.
Las piernas caen de la cama, taquicardia, caída a un precipicio, agitación y desesperación, mareos, incapacidad para pedir ayuda, temor a ser perseguido y dolor en el pecho. 


\section{Visiones}

HG

Rostros, sombras moviéndose, figuras oscuras o negras, siluetas humanas, imágenes de personas conocidas, un hombre parado frente a mí, insectos, luces, paisajes, paredes, situaciones del día.
HP

Rostros, paisajes, figuras humanas, luces espiraladas, restos de sueños, sombras con formas humanas, fantasmas.
Las visiones tienden a ser ricas en contenido, están bajo el control de la persona que las experimenta (a diferencia de las alucinaciones) y ocurren en un $27 \%$ para el periodo $\mathrm{HG}$ y $15 \%$ para el periodo HP. La mayoría de estas experiencias tienen lugar a ojos cerrados (18\%-8\%), tienden a ser en colores (18 \%-8 \%) y están relacionadas con ros- tros, luces de varias formas, y paisajes, a veces en movimiento (no especifica si a ojos abiertos o cerrados) durante el periodo HG. Durante el periodo HP las visiones son bastante similares, a menudo confundidas con restos de sueños, pero predominan las figuras con formas humanas y espirituales.

\section{Sensación de que hay alguien o algo en la habitación}

\section{HG}

Algo hostil, atemorizante, sentirme acompañada/contenida, algo se aproxima a mi dormitorio pero que aún no llega, escalofríos, espíritus amenazantes, sensación de que camina por mi habitación, sensación de que mi madre/mi padre que me observa.
Algo o alguien detrás de mí, extraña sensación, amenazante, sensación de que varias personas están ahí, sensación de que alguien se despide de mí.
La sensación de presencia es un rasgo común de la mayoría de las experiencias $\mathrm{HG} / \mathrm{HP}$, las cuales varían en sus características e impacto emocional. En esta muestra ocurren en un 20 $\%$ para el periodo HG y $14 \%$ para el periodo HP. Un indicador emocional común es su carácter negativo, descritas como hostiles y amenazantes, en su mayoría, o placenteras en otras durante el periodo HG. La sensación de presencia durante el periodo HP es bastante similar, aunque tiende a ser invariablemente más negativa que en el HG. 


\section{Movimientos o sonidos «reales»}

\begin{tabular}{ll}
\hline HG & \multicolumn{1}{c}{ HP } \\
\hline $\begin{array}{l}\text { Girar mi cuerpo en la cama, recibir un beso, } \\
\text { contracciones musculares, dar patadas, } \\
\text { gritos al salir de una pesadilla, hablar con } \\
\text { mi pareja/compañero de cama, mover los } \\
\text { pies, movimientos involuntarios del cuerpo }\end{array}$ & $\begin{array}{l}\text { Moverme antes de abrir los ojos, risas, } \\
\text { despertador, estirarme, caminar fuera de } \\
\text { la cama, levantarme repentinamente, llorar, } \\
\text { oír ronquidos, oír murmullos, tener sexo, } \\
\text { y los miembros, hablarme a mí mismo en }\end{array}$ \\
$\begin{array}{l}\text { voz alta, risas, ronquidos de mi pareja/ } \\
\text { compañero de cama, tener sexo, temblores, } \\
\text { masturbación/orgasmos, bostezar. }\end{array}$ & \\
\hline
\end{tabular}

La habilidad de distinguir lo «real» de lo que no lo es constituye una característica salugénica de muchas experiencias HG/HP y tener control sobre lo que ocurre en el entorno en los momentos previos al sueño (18\%) y al despertar (9,6\%). Los movimientos nocturnos, contracciones musculares, actividad sexual y ronquidos son experiencias reales comunes durante el periodo $\mathrm{HG}, \mathrm{y}$ movimientos previos al abrir de ojos u otros estímulos externos (por ejemplo, el despertador) durante el HP.

\section{Audiciones}

HG

Voces que me hablan, la música de mi canción favorita, zumbidos, conversaciones de otras personas desconocidas, gritos, golpes, melodías, murmullos, música indefinida, canto de pájaros, pies que se arrastran al caminar, olas del mar, muebles crujiendo, bocina de tren.
Las audiciones, después de las visiones, también tienden a ser ricas en contenido, y son más susceptibles de interpretar como experiencias alucinatorias perturbadoras, generando mayor confusión y temor. Ocurren en el 15,8 \% para el periodo $\mathrm{HG}$ y $11,9 \%$ para el pe- riodo HP. La mayoría de estas experiencias contienen voces, conversaciones o diálogos de otras personas y melodías durante el periodo HG. Durante el HP las audiciones incluyen voces, melodías y respiraciones. 


\section{Sensación de tocar o ser tocado por alguien o algo}

\begin{tabular}{ll}
\hline HG & \multicolumn{1}{c}{ HP } \\
\hline $\begin{array}{l}\text { Caricias en la frente, caricias en la mano y } \\
\text { el pelo, insectos, golpes en la espalda, jalan } \\
\text { o tocan mis piernas, varias manos que me } \\
\text { acarician, una mano se apoya en mi espal- }\end{array}$ & $\begin{array}{l}\text { Sacudones, golpes, jalan o tocan mis pier- } \\
\text { nas, me tocan el hombro, roces, me aplasta } \\
\text { da, empujones, roces, me toman del cuello, } \\
\text { me ahorcan, abrazos, sacudidas. }\end{array}$ \\
\end{tabular}

La sensación de tocar o ser tocado es también un rasgo común de la mayoría de las experiencias HG/HP. Ocurren en un $14,7 \%$ para el periodo HG y algo menos (10\%) para el periodo HP. Un indicador emocional común es un carácter positivo o inofensivo y a veces negativo agresivo, descritas como caricias o empujones. Parece que la mano de otro/a es la forma de contacto usual, y más rara vez patadas o abrazos. La sensación de ser «aplastado» en el pecho es una característica negativa común durante el periodo HP.

\section{Incapacidad para moverse o hablar}

\begin{tabular}{ll}
\hline HG & HP \\
\hline $\begin{array}{l}\text { Desesperación, impotencia, ahogo, paráli- } \\
\text { sis en la mandíbula, las piernas y brazos, }\end{array}$ & $\begin{array}{l}\text { Desesperación, dolor, impotencia, temor a } \\
\text { no poder despertar, miedo a morir. }\end{array}$ \\
$\begin{array}{l}\text { incapacidad para abrir los ojos, incapaci- } \\
\text { dad para gritar, sensación de peligro, algo }\end{array}$ & \\
demoníaco. & \\
\hline
\end{tabular}

La incapacidad para moverse o hablar es un rasgo invariable de ciertas experiencias HG (14 \%) y HP (11,5\%), que conducen a reacciones emocionales tales como desesperación, impotencia, ahogo y la incapacidad de gritar como un pedido de auxilio frente al miedo de morir o al temor a no despertar. 


\section{Movimientos}

HG

HP

Caminar, hablar, correr, caída a un pozo, bailar, pisar mal el cordón de una vereda, tropezar, intentar inútilmente de levantarse, deseo sexual, sobresaltos.
Caminar, bailar, correr, bote movido por olas, empujones, jugar al futbol, movimientos incontrolados, sacudidas.
La sensación subjetiva de ejecutar movimientos a pesar de estar a punto de dormir en la cama es una experien- cia más común en el periodo HG (11\%) que en el HP (7\%), tales como caminar, hablar o correr para ambos periodos.

\section{Sensación inusual relacionada con su cuerpo}

\section{HG}

Rigidez corporal, bienestar y gran paz, electrocución, agitación, sensación de caer de una hamaca, cansancio físico, contracturas, sentirme paralizado, brisas, me vi a mí mismo durmiendo.
HP

Inmovilidad, sensación de caer de la cama, mi cuerpo y mi mente desconectadas, miedo por no poder despertar, pesadez, sofocamiento.

\section{Sensación no mencionada en preguntas anteriores}

\section{HG}

Desconcierto, confusión, mareos, experiencia placentera, sordera momentánea, sensación de volar, inmensa felicidad.
HP

Deseos de continuar durmiendo, frustración, tristeza.
Otras sensaciones corporales inusuales reportadas en periodos $\mathrm{HG}(8 \%) \mathrm{y}$ HP (6\%) incluyen una amplia gama de otras sensaciones no antedichas, tales como electricidad, brisas, rigidez cor- poral, pesadez, y observarse a sí mismo en la cama. También emociones positivas en el periodo $\mathrm{HG}$, tales como la sensación de volar, o en el periodo HP, deseos de continuar durmiendo. 


\section{Olores}

\section{HG}

Quemado, comida, chocolate fuerte, putrefacción de un cuerpo humano, flores/cementerio, perfume, rosas.
HP

Comida, flores, perfumes varios, tostadas con miel y manteca.

\section{Sabores}

HG

Carne asada y comidas varias.
HP

Caramelos, copos con leche, mal aliento.
Si se examinan los tipos de olores experimentados durante los periodos HG y HP, parece haber un número relativamente pequeño de temas, tales como olor a quemado, a podrido o a perfumes en HG (5\%) y comidas, flo- res y perfumes durante el HP (6\%). A causa de que muchos olores están también asociados a sabores, las comidas son temas recurrentes en $\mathrm{HG}(3 \%)$ y los dulces en el HP (3\%).

\section{Diferencias/similitudes con los sueños}

\section{HG}

Son diferentes, desagradables, menos intensos que el sueño.
Son diferentes, menos intensos que el sueño, pero son más pacíficas.

\section{Posibles interpretaciones para estas experiencias}

\section{HG}
Alucinaciones, efectos del cansancio, men- sajes interiores, mensajes de otras perso- nas, sueños, demonios, espíritus, contacto interdimensional, no tengo ninguna inter- pretación.

HP
HP

Efectos del cansancio, experiencias raras pero normales, anuncios o advertencias de algo malo o inminente, no tengo ninguna interpretación, espíritus, demonios. 
Muchos encuestados expresaron que las experiencias $\mathrm{HG} / \mathrm{HP}$ eran sustancialmente diferentes del recuerdo de un sueño. De hecho, algunos fueron capaces de interpretarlas como alucinaciones, efectos del cansancio, pero también de espíritus de los muertos. Otros indicaron no tener ninguna interpretación para estas experiencias.

\section{Análisis estadístico}

Con el total de la suma de las respuestas afirmativas para cada ítem de cada periodo (HG y HP) de la encuesta (el puntaje alto indica mayor frecuencia de experiencias $\mathrm{HG} / \mathrm{HP}$ ) se llevó a cabo una comparación de género de las puntuaciones de HG/HP. El resultado muestra que ambos periodos dieron significativamente a favor de las mujeres, es decir, ellas tienden a experimentar más experiencias HG $(\mathrm{p}=.03)$ y HP $(\mathrm{p}=.01)$ en comparación con los varones (véase la tabla 2).

Se llevó a cabo una correlación entre experiencias $\mathrm{HG} / \mathrm{HP}$ y otras variables, tales como edad, grado de espiritualidad, frecuencia en el recuerdo del sueño y nitidez de las imágenes del sueño.

Aunque no se encontró una relación con la edad, sin embargo, se observó que ambos periodos están positiva y

Tabla 2

Comparación de género en experiencias HG/HP

\begin{tabular}{lcccccc}
\hline Estado & Min.-Max. & $\begin{array}{c}\text { Media (DT) } \\
\text { Varones }\end{array}$ & $\begin{array}{c}\text { Media (DT) } \\
\text { Mujeres }\end{array}$ & $\begin{array}{c}\text { Ude } \\
\text { Mann-Whitney }\end{array}$ & $\mathbf{z}$ & $\mathbf{p}$ \\
\hline Hipnagógico & $0-12$ & $1,58(2,22)$ & $1,91(2,24)$ & 21102,500 & $-2,087$ &, 037 \\
Hipnopómpico & $0-12$ & $0,81(1,75)$ & $1,23(2,15)$ & 20867,500 & $-2,487$ &, 013 \\
\hline
\end{tabular}

Nota.- La puntuación mínima representa sin experiencia (HGN =161, 36,9\%; HPN=260, 59,6\%), la puntuación máxima(12) representa a individuos que han respondido afirmativamente todas las preguntas (HG y HG N =6, 1,4\%). Solo 102 (23,4\%) indicaron haber tenido al menos una experiencia HG y 90 (20,6\%) una experiencia HP. Los ítems 13 y 14 fueron excluidos. 
Tabla 3

Correlación entre edad, frecuencia y nitidez del recuerdo de sueños y espiritualidad con experiencias HG/HP

\begin{tabular}{lcccc}
\hline \multicolumn{1}{c}{ Estado } & Edad & Espiritualidad & Frecuencia & Nitidez \\
\hline Hipnagógico &,- 069 &, $183^{* *}$ &,$- 253^{* *}$ &,$- 249^{* *}$ \\
Hipnopómpico &, 021 &, $161^{* *}$ &,$- 208^{* *}$ &,$- 237^{* *}$ \\
\hline Nota: ** $p<.001$ & & & \\
Siendo $1=$ «no soy espiritual» a $4=$ «soy extremadamente espiritual». & \\
Siendo $1=$ «casi nunca» a $4=$ «casi todas las mañanas». \\
Siendo $1=$ «muy vaga y difusa» a $5=$ «perfectamente clara e intensa».
\end{tabular}

significativamente relacionados con la espiritualidad $(\mathrm{p}<.001)$, la frecuencia en el recuerdo del sueño $(\mathrm{p}<.001)$ y la nitidez de las imágenes del sueño $(\mathrm{p}<$ .001) (véase la tabla 3).

\section{DISCUSIÓN}

Los resultados de esta encuesta proporcionan gran cantidad de información sobre el contenido y las características de la imaginería HG y HP sobre una muestra de la población general. Estos hallazgos sugieren que la imaginería HG/HP más común es la sensación de caída, imaginería visual a ojos cerrados, sensación de presencia, imaginería auditiva, sensación de contacto e incapacidad para hablar o moverse. La imaginería olfativa y gustativa son relativamente raras. También la imaginería HG parece ser más común que la HP. Aunque el contenido de la imaginería HG/HP es bastante amplio, un análisis cualitativo de los datos de la encuesta revela que hay temas comunes que se aplican a ambos periodos HG y HP. Sin embargo, hay algunos temas y características que parecen ocurrir más en el periodo HG que en el HP. Estos resultados confirman e incluso amplían parcialmente otras clasificaciones (Leaning, 1925; Mavromatis, 1987; Sherwood, 2012).

Por otra parte, personas con altas puntuaciones con experiencias HG/HP tendieron a mostrarse más espirituales, lo cual podría tener relación con la tendencia a explicar de modo sobrenatural algunas de estas experiencias. También es interesante la relación positiva con el recuerdo del sueño y la nitidez de las imágenes del sueño. Sin embargo, las personas con experiencia HG/HP tienen mayor labilidad para el recuerdo del sueño así como también para experimentar sueños vívidos y realistas, y esto aumenta la probabilidad de experimentar más imaginería $\mathrm{HG} / \mathrm{HP}$, lo 
cual confirma estudios previos usando la técnica psicomanteum (Parra \& Villanueva, 2010).

En el estudio de Sherwood (2012) se empleó la misma encuesta por internet a 492 participantes, para determinar la frecuencia de las modalidades sensoriales de imaginería HG y HP, su contenido y cómo son interpretadas. Al igual que nuestro estudio, sus resultados sugieren que la imaginería HG es más común que la HP; pero Sherwood observó que la imaginería visual (HG $81 \%$; HP $71 \%$ ), la sensación de caída (HG 76 $\%$; HP $50 \%$ ) y la sensación de presencia (HG $73 \%$; HP $58 \%$ ) (en ese orden) eran las formas más comunes, seguidas por imaginería auditiva (HG 59 \%; HP 50 \%), sensaciones táctiles (HG $57 \%$; HP $53 \%$ ), corporal y movimientos. Al igual que en el presente estudio, la imaginería olfativa (HG $18 \%$; HP $19 \%$ ) y gustativa (HG $9 \%$; HP $14 \%$ ) era escasa. Una ventaja por sobre el estudio de Sherwood, que reclutó casos que provienen de una muestra de interesados en las experiencias HG/HP por internet, es que la presente muestra es más representativa de la población general.

Aparte de la obvia diferencia entre la imaginería HG y la HP, estos dos periodos también pueden diferir. La principal diferencia es que el contenido HP está en relación (pero no siempre) con sueños anteriores, mientras que el HG no tiende a ser así. En sentido temporal, parece que la imaginería HG corresponde a eventos antes de dormir, mientras que la imaginería HP tiende a anticipar acontecimientos cotidianos que pueden seguir al sueño (McKellar, 1957). No es de extrañar que la HP tenga mayores asociaciones con sueños que la imaginería $\mathrm{HG}$, en particular dada la primera definición de imaginería hipnagógica sugerida por F. W. H. Myers (1903), que describe a la imaginería de los sueños que persisten en la vigilia. Sin embargo, parece que la imaginería HP no siempre está asociada a sueños anteriores (ver Mavromatis, 1987, p. 39.) y así tal vez se deberían clasificar dos tipos de imaginerías HP (Leaning, 1925): 1) la imaginería relacionada con el sueño persistente; 2) y la imaginería que no está relacionada con el sueño. Los participantes sugieren que a veces los sueños parecen provenir o elaborarse en virtud de imaginería hipnagógica previa. Los resultados de la encuesta también sugieren que ciertos temas pueden ser característicos de la imaginería hipnagógica, y, por tal razón, es importante mantener la distinción entre la imaginería HG y la HP.

También se identificó una serie de posibles interpretaciones de las experiencias $\mathrm{HG} / \mathrm{HP}$. Algunas personas parecen no prestar demasiada atención o no están seguras de lo que son, otros las consideran aspectos normales del funcionamiento de la mente/cuerpo, o están preocupados por posibles problemas de salud física o mental. Otros consideran que tienen algún tipo de causa paranormal, espiritual, mística o 
sobrenatural, aunque tales interpretaciones no son sorprendentes, dadas las similitudes entre ciertas características $\mathrm{HG} / \mathrm{HP}$ y varios tipos de experiencias anómalas.

Hay evidencia que sugiere que los estados HG/HP podrían ser facilitadoras de varios tipos de experiencias anómalas, o que las experiencias $\mathrm{HG} / \mathrm{HP}$ se pueden malinterpretar, o ambas. Las interpretaciones paranormales tienden a asociarse, como sería esperable, a procesos y agentes que comparten características similares: por ejemplo, la percepción extrasensorial, el contacto con los muertos, las apariciones y las experiencias fuera del cuerpo. Otras interpretaciones pueden ser ángeles/demonios, algún tipo de fuerza sobrenatural o extraña y seres de otras dimensiones. Las interpretaciones relacionadas con ovnis parecen ser muy poco frecuentes, y en este estudio están totalmente ausentes, al igual que las interpretaciones psicokinéticas. En otros estudios se ha sugerido que las experiencias HG/HP se pueden interpretar plausiblemente como percepción extrasensorial, apariciones, experiencias fuera del cuerpo y experiencias cercanas a la muerte, recuerdos de vidas pasadas, experiencias místicas y religiosas, abducciones alienígenas y daños por brujería o ataque de espíritus malignos o demonios (Blackmore, 1998; Hufford, 1982; Leaning, 1925; Liddon, 1967; McKellar, 1957, 1989; Spanos et al., 1993; Wilson y Barber, 1983).
Hay ciertas características en los estados HG y HP que podrían conducir a interpretaciones en términos de comunicación con los muertos. Por ejemplo, las visiones de rostros, que a veces resultan agradables y otras aterradoras, pueden convertirse en figuras que se acercan al durmiente (Leaning, 1925; Mavromatis, 1987; McKellar, 1957); las voces, por ejemplo oír que lo llaman por su nombre, el sonido de pisadas, la sensación de presencia o de ser vigilado u observado, olores asociados a una persona fallecida y la sensación de ser tocado o de alguien sentado o acostado en la cama, todas estas pueden contribuir a tales interpretaciones. Algunas experiencias de encuentros con seres queridos fallecidos en la cámara de psicomanteum (Moody, 1993), comparten características de las imágenes hipnagógicas. Algunas experiencias fuera del cuerpo (EFC) suelen presentarse durante el estado hipnagógico y existen varias similitudes entre la imaginería HG y las características de las EFC, como las sensaciones de flotar y volar, las visiones durante la salida del cuerpo, los cambios en la imagen corporal, sentimientos de estar disociado del cuerpo y las condiciones en que estas se producen (Mavromatis, 1983, 1987; Parra, 2009).

Además del contenido específico, hay una serie de características en las experiencias HG/HP que pueden hacerlas parecer reales y facilitar falsas interpretaciones. Un ejemplo de ello es 
el hecho de que puede ser difícil determinar si uno está despierto o dormido, puede sentirse más consciente que durante el sueño y estar consciente del entorno que lo rodea; las experiencias pueden ocurrir a ojos abiertos o cerrados (aunque casi siempre cerrados) y pueden implicar más de una modalidad sensorial (Cheyne, Newby-Clark, Rueffer, 1999). No obstante, algunas experiencias $\mathrm{HG} / \mathrm{HP}$ pueden no tener ninguna similitud con las experiencias anómalas, y estar vinculadas a pensamientos, deseos, necesidades, preocupaciones, fantasías o sueños.

Ciertamente, no siempre la imaginería $\mathrm{HG} / \mathrm{HP}$ o la parálisis del sueño da cuenta de todas las formas de experiencias anómalas; por ejemplo, muchas de estas experiencias se presentan durante la vigilia u ocupado en otras actividades. Las similitudes pueden deberse a que algunas experiencias anómalas son malinterpretaciones de experiencias HG/HP normales, o las características de los dos tipos de experiencias pueden compartir mecanismos o procesos similares. Sin embargo, como no entendemos completamente cuáles son las causas de ciertas experiencias anómalas, tampoco las causas y los mecanismos que participan en los periodos $\mathrm{HG} /$ HP. Esperamos que este estudio pueda ayudar a comprender mejor el contenido de las experiencias HG/HP y cómo se interpretan.
Finalmente, lo que necesitamos es identificar qué distingue las experiencias HG/HP normales de las anómalas, aunque esto es más fácil decirlo que hacerlo. Tal vez podría haber algunas diferencias cualitativas entre las experiencias HG/HP que parecen implicar procesos anómalos y otras que no. Siempre es más difícil evaluar ciertas experiencias consideradas paranormales, sobre todo si no hay evidencia que lo corrobore, pero es posible que el conocimiento de las experiencias $\mathrm{HG} /$ HP pueda actuar como una frontera que delimita la evaluación de la validez de tales experiencias.

\section{REFERENCIAS}

American Sleep Disorders Association (1990). International classification of sleep disorders: Diagnostic and coding manual (ICSD). Rochester, $\mathrm{MN}$ : American Academy of Sleep Medicine.

Blackmore, S. (1998). Abduction by aliens or sleep paralysis? Skeptical Inquirer, 22(3), 23-28.

Cheyne, J. A., Newby-Clark, I. R., \& Rueffer, S. D. (1999). Relations among hypnagogic and hypnopompic experiences associated with sleep paralysis. Journal of Sleep Research, 8, 313-317.

Flick, U. (1998). An introduction to qualitative research. Thousand Oaks, CA: Sage. 
Foulkes, D., \& Vogel, G. (1965). Mental activity at sleep onset. Journal of Abnormal Psychology, 70, 231-246.

Gillespie, G. (1997). Hypnopompic imagery and visual dream experience. Dreaming, 7, 187-194.

Glicksohn, J. (1989). The structure of subjective experience: Interdependencies along the sleepwakefulness continuum. Journal of Mental Imagery, 13, 99-106.

Gurney, E., Myers, F. W. H., \& Podmore, E. (1886). Phantasms of the living (Vol. 12). Londres: Trabner.

Hori, T., Hayashi, M., \& Morikawa, T. (1994). Topographical EEG changes and the hypnagogic experience. En R. D. Ogilvic, \& J. R. Harsh (Eds.), Sleep onset: Normal and abnormal processes (pp. 237-253). Washington, DC: American Psychological Association.

Hufford, D. J. (1982). The terror that comes in the night: An experiencecentered study of supernatural assault traditions. Philadelphia, PA: University of Pennsylvania Press.

Lavie, P. (1996). The enchanted world of sleep. New Haven, CT: Yale University Press.

Leaning, E. E. (1925). An introductory study of hypnagogic phenomena. Proceedings of the Society for Psychical Research, 3(5), 287-411.
Liddon, S. C. (1967). Sleep paralysis and hypnagogic hallucinations: Their relationship to the nightmare. Archives of General Psychiatry, 17, 88-96.

Maury, M. A. (1848). Des hallucinations hypnagogiques, on des erreurs des sens dans l'état intermediaire entre la veille et le sommeil. Annales Medico-Psychologiques System Nerveux, 11, 26-40.

Mavromatis, A. (1987). Hypnagogia: The unique state of consciousness between wakefulness and sleep. Londres: Routledge \& Kegan Paul.

McCreery, C. (1993). Schizotypy and outofthebody experiences. Oxford, UK: University of Oxford. (Tesis doctoral no publicada).

McKellar, P. (1957). Imagination and thinking. A psychological analysis. Londres: Cohen \& West.

McKellar, P. (1989). Abnormal psychology: Its experience and behaviour. Londres: Routledge.

McKellar, P., \& Simpson, L. (1954). Between wakefulness and sleep: Hypnagogic imagery. British Journal of Psychology, 45, 266-276.

Moody, R. (1993). Reencuentros: Contactos con seres queridos fallecidos tras su muerte. Madrid: Edaf.

Myers, F. W. H. (1903). Human personality and its survival of bodily 
death (Vol. I.). Nueva York: Longmans, Green.

Nielsen, T. A. (1992). A self-observational study of spontaneous hypnagogic imagery using the upright napping procedure. Imagination, Cognition and Personality, 11, 353-366.

Ohayon, M. M., Priest, R. G., Caulet, M., \& Guilleminault, C. (1996). Hypnagogic and hypnopompic hallucinations: Pathological phenomena? British Journal of Psychiatry, 169, 459-467.

Oswald, 1. (1962). Sleeping and waking. Amsterdam: Elsevier.

Parra, A. (2009). Experiencias alucinatorias nocturnas: Relación con la esquizotipia, tendencias disociativas y propensidad a la fantasía. Revista Internacional de Psicología, 43, 134-143.

Parra, A. \& Villanueva, J. (2010). Unusual perceptual experiences and ESP under psychomanteum stimulation: Imagery/hallucination proneness and schizotypal personality measures. Australian Journal of $\mathrm{Pa}$ rapsychology, 10(2), 120-139.

Rechtschaffen, A. (1994). Sleep onset: Conceptual issues. En R. D. Ogilvie \& J. R. Harsh (Eds.), Sleep onset: Normal and abnormal processes (pp. 3-18). Washington, DC: American Psychological Association.
Richardson, J. T. E., Mavromatis, A., Mindel, T., \& Owens, A. C. (1981). Individual differences in hypnagogic and hypnopompic imagery. Journal of Mental Imagery, 5, 91-96.

Rose, N., \& Blackmore, S. (1996, August). Two pilot surveys of unusual personal experiences. Paper presented at the 20th International Conference of the Society for Psychical Research, Londres: Cirencester.

Schacter, D. L. (1976). The hypnagogic state: A critical review of the literature. Psychological Bulletin, 83, 452-481.

Sherwood, S. J. (1999). Relationship between childhood hypnagogic/ hypnopompic and sleep experiences, childhood fantasy proneness, and anomalous experiences and beliefs: An exploratory www survey. Journal of the American Society for Psychical Research, 93, 167-197.

Sherwood, S. J. (2000). A comparison of the features of psychomanteum and hypnagogic/hypnopompic experiences. International Journal of Parapsychology, 11, 97-121.

Sherwood, S. J. (2002). Relationship between the hypnagogic/hypnopompic states and reports of anomalous experiences. Journal of Parapsychology, 66, 127-150. 
Sherwood, S. (2012). A web survey of the content, sensory modalities, and interpretation of hypnagogic and hypnopompic experiences. Journal of Parapsychology, 76, 27-56.

Spanos, N. R., Cross, P. A., Dickson, K., \& DuBreuil, S. C. (1993). Close encounters: An examination of UFO experiences. Journal of Abnormal Psychology, 102, 624-632.

Tart, C. T. (1969). Altered states of consciousness. Nueva York: Wiley. 